\title{
Influence of climatic conditions on tympanic temperature and milk production in grazing cows
}

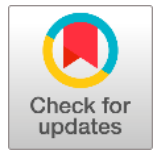

\author{
Mauricio Veléz-Terranova ${ }^{a}$ (i) | Raúl Molina ${ }^{\text {iD }}$ | Hugo Sánchez ${ }^{\text {iD }}$ | \\ Rómulo Campos $^{2}$ | Sandra Perilla ${ }^{b}$
}

Departamento de Ciencia Animal, Universidad Nacional de Colombia, Palmira, Colombia.

Estudiante Maestría en Ciencias Agrarias, área Producción Animal Tropical, Universidad Nacional de Colombia, Palmira, Colombia.

*Corresponding author: ovelez@unal.edu.co

\begin{abstract}
The present study aimed to analyze large volumes of tympanic temperature (TT) data to identify its use as a physiological indicator of climatic conditions and its relationship with milk production in grazing cows under tropical lowland conditions. Three dairy farms and 21 multiparous early lactation cows were included in the study. Seven animals were equipped with tympanic temperature wireless sensors within each farm, and permanent information was collected hourly for 22 days on average. Ambient temperature (AT), relative humidity (RH), wind speed (WS), precipitation (PP), and THI information were obtained from meteorological stations located close to each farm. Statistical analyses included Spearman correlations and random coefficient regression models $(P<0.05)$. TT presented moderate and significant correlations with AT (0.35 to 0.49$)$, SR (0.25 to 0.32$)$, THI (0.35 to 0.49$)$, and RH ( -0.35 to -0.49$)$. Climatic variables like AT, PP, SR, and WS were the most contributing factors to TT prediction $\left(R^{2}=0.42\right.$ to 0.86$)$. Grazing dairy cows in tropical scenarios accumulate heat during the day and dissipate it at nighttime, although higher producing animals deal with more problems to reach thermal homeostasis. Correlations between TT and daily milk production varied according to animal yield; however, higher $\Pi$ values were related to the most productive cows. The effect of $\pi$ on milk production prediction was not conclusive among farms, possibly by animal management or others characteristics of the systems. TT determination through remote sensors allows a reliable diagnosis of the physiological temperature response to climatic conditions.
\end{abstract}

Keywords body temperature, dairy cows performance, grazing systems, sensors

\section{Introduction}

In Latin America, dairy production with grazing cows was consolidated (Gama et al 2020). This production model must incorporate technologies that allow better studies on adaptation, especially for the highest dairy producing breeds that usually have adaptive limitations in tropical conditions (Sejian et al 2018). IoT technologies have become an attractive research tool since it allows monitoring routine activities with animals, without restrictive handling, immobilization, or altering natural behavior. (Akbar et al 2020).

In tropical conditions, multiple stressors are present, and their influence on dairy cows is likely to be more intense due to climate change. Heat stress has been recognized as one of the major problems affecting dairy farms and their highest producing animals (Sejian et al 2018; Arias et al 2018). Milk production generates high energetic costs for net lactation, which increase when climatic conditions are unfavorable (Mylostyvyi and Chernenko, 2019; Daltro et al 2020), especially for animals of Bos taurus origin, exploited in low tropic ecosystems (Hernández-Castellano et al 2019). Nutritional requirements are solved by increasing energy density, which is not economically feasible in pasture-based production systems (Morales-Vallecilla and Ortiz-Grisales 2018). Productive limitations due to climatic adaptation have only been partially studied from the racial component (Gama et al 2020). However, a complete understood of animals adaptation requires the description of other parameters like body temperature since it is correlated with other physiological variables such as respiratory and heart rate (Vasconcelos et al 2020). Another possibility is to know physiological mechanisms that can be analyzed to provide management alternatives to compensate for climatic alterations and potentiate the physiological responses of animals that can express adaptation mechanisms faster or more efficiently.

The effect of environmental and physiological heat load on animal's body temperature is an important parameter to evaluate health status (Liu et al 2019; Vasconcelos et al 2020). Animal's body temperature is traditionally estimated through rectal and vaginal measurements; however, alternative methods like tympanic temperatures (TT) also constitute a reliable measure since some studies reported no statistical difference with rectal temperatures (Sellier et al 2014; Shu et al 2021) and high correlation with vaginal temperature $(r=0.77$; Bergen and Kennedy, 2000). The differences associated with the anatomical sampling point and its response time were also validated in other studies (Scharf et al 2011; Sellier et al 2014; Godyń et al 2019). TT is an attractive alternative measure 
since it can be monitored through fixed sensors localized inside the cow's tympanic canal to obtain a high volume of real-time information that can be wirelessly transmitted and analyzed by big data algorithms (Jara et al 2016). This method increases the data volume for analysis and reduces the stress and time spent with traditional body temperature recording methods.

Tympanic temperature determination has been performed with good results in dairy cattle (Jara et al 2016; Shu et al 2021). The relationship of physiological responses of animals varies according to the ecological zone and their respective climate conditions (Silva et al 2021). This observation reinforces the need to evaluate the animal's response to particular productive scenarios to analyze adaptive processes and keep contributing to study the associations between climate and milk production under grazing conditions, especially in tropical areas where this activity has been showing a sustained growth and offers an agribusiness opportunity for its population in the coming years. The objective of the present work was to analyze large volumes of tympanic temperature data to identify its use as a physiological indicator of climatic conditions and its relationship with milk production in grazing cows under tropical lowland conditions.

\section{Materials and Methods}

\subsection{Location and animals}

All experimental interventions on the animals involved in the present project were approved by the ethics and animal welfare standards committee of the Universidad Nacional de Colombia, campus Palmira.

Production systems: The study was carried out in three dairy cattle production systems under low tropics conditions, located between $3^{\circ} 30$ ' to $4^{\circ} 10^{\prime} \mathrm{N}$ and $76^{\circ} 21^{\prime}$ to $76^{\circ} 46^{\prime} \mathrm{W}$, corresponding to a tropical dry forest zone according to the Holdridge classification. Within each system, a unique racial group-oriented to milk production was found. The main characteristics of the evaluated farms are observed in Table 1. In total, twenty-one milking cows (seven per system) in early lactation and with more than three calving were monitored.

\subsection{Climatic variables}

Climate information was obtained from three climatic stations belonging to the automated meteorological network of the sugarcane research center "Cenicaña". The closest meteorological station was assigned to each farm, ensuring that the distance between them did not exceed $6 \mathrm{~km}$. Daily hourly data capture of ambient temperature (AT - $\left.{ }^{\circ} \mathrm{C}\right)$, solar radiation ( $\left.\mathrm{SR}-\mathrm{cal} / \mathrm{cm}^{2}\right)$, relative humidity $(\mathrm{RH}-\%)$, wind speed (WS $-\mathrm{m} / \mathrm{s}$ ), and precipitation (PP - $\mathrm{mm}$ ) were analyzed. Ambient temperature and relative humidity variables were used to construct the temperature and humidity index (THI) using the equation proposed by Barrera (2015) for grazing cattle under tropical conditions.
$\mathrm{THI}=1.8 * \mathrm{Ta}+\left[\mathrm{RH}^{*}(\mathrm{Ta}-14.4)\right]+46.4$

where: $\mathrm{Ta}$ is the average daily temperature $\left({ }^{\circ} \mathrm{C}\right), \mathrm{RH}$ is the daily mean relative humidity (\%). The average range of climatic variables during the experimental period is presented in Table 1.

\subsection{Measured variables}

The physiological tympanic temperature was used as an indicator of animal body temperature (Jara et al 2016). Tympanic temperature measurements were obtained through a wireless sensor installed manually in the tympanic canal of the cows; permanent information was collected every hour for 22 days on average through an electronic data collection mechanism type earmuff (Figure 1). Data was transmitted via Bluetooth ${ }^{\mathrm{TM}}$ to a cell phone application. The residence time of the sensors in the animals varied between systems and between animals. The estimation of tympanic temperature through sensors has been validated with traditional rectal and vaginal temperatures recording methods (Sellier et al 2014; Bergen and Kennedy, 2000) and its response time and anatomical sampling point (Scharf et al 2011; Godyń et al 2019).

\subsection{Statistical analysis}

In a first step, the relationship between environmental variables and animal tympanic temperature were studied for each farm using Spearman Correlation analysis. Subsequently, regression models with random coefficients were evaluated in order to predict tympanic temperature from environmental variables. Previous correlation analysis indicated that $\mathrm{AT}, \mathrm{RH}$, and $\mathrm{THI}$ climatic variables were highly associated (>0.90). To avoid multicollinearity effect as a consequence of highly correlated predictors, three analysis models were established:

$y=B_{0}+B_{1} X+B_{2} P P+B_{3} S R+B_{4} W S+B_{5} D+C+e$

where $B_{0}$ is the intercept, $B_{1}, B_{2}, B_{3}, B_{4}$, and $B_{5}$ are regression coefficients of the independent variables, $X$ could be ambient temperature $\left(\mathrm{AT}-{ }^{\circ} \mathrm{C}\right)$, or relative humidity $(\mathrm{RH}-\%)$ or temperature-humidity index (THI), PP (precipitation $-\mathrm{mm}$ ), SR (solar radiation $-\left(\mathrm{cal} / \mathrm{cm}^{2}\right)$, WS (wind speed $-\mathrm{m} / \mathrm{s}$ ), D (measurement day $14-20$ ), $C$ (random cow effect) and $e$ (random error effect). To satisfy normality and heteroscedasticity assumptions of residuals, it was necessary to eliminate outliers with standardized residuals above and below 3.30 and -3.30 , respectively (according to the residual Vs predicted graph). The best-adjusted model was selected through Akaike and Bayesian coefficients. All analyzes were performed using the Infostat software (Di Rienzo et al 2017).

The same procedures mentioned above were carried out with the joined climatic and tympanic temperatures information of the three analyzed production systems to establish general models with greater inference capacity. In this case, the models were the same as equation 2; however, the farm $(1,2$, or 3$)$ effect was also included, and the cow nested to the farm was the random effect. The joined 
information consisted of 8.781 records, where $70 \%$ ( $\mathrm{n}=$ 6.146) were used to train the models and the rest $30 \%$ ( $n=$ $2.635)$ as the validation data. The analyses were carried out in the RStudio (2020) package version 4.0.2.

A second analysis was performed to evaluate the association between animal tympanic temperature and milk production. In this case, the daily average tympanic temperature per cow was estimated within each farm and related to the respective daily milk production. Pathological tympanic temperature values equal or higher than $39.8{ }^{\circ} \mathrm{C}$ were not included in the study. Analysis was carried out for each farm because average cows' performance within the systems were different ( 5 to $14 \mathrm{Kg} /$ day). Variables relationships were evaluated through Spearman correlation analysis. Also, regression models with random effects (cow) were adjusted to predict daily milk production within each farm, including the day (10 to 26), tympanic temperature, and their quadratic terms as predictors. When quadratic effects were significant, the maximum values reached were estimated through equating to zero the adjusted model first derivative and solving for the unknown term. Analyzes were performed using the Infostat software (Di Rienzo et al 2017).

Table 1 Characteristics and climatic conditions of the farms included in the study.

\begin{tabular}{|c|c|c|c|}
\hline Farm & 1 & 2 & 3 \\
\hline Production system & Grazing & Silvopastoralism & Grazing \\
\hline Type and number of milkings & Mechanical - Double milking & Mechanical - Double milking & Mechanical - Single milking \\
\hline Forage base & Cynodon nlemfuensis & $\begin{array}{l}\text { Cynodon nlemfuensis + Leucaena } \\
\text { leucocephala }\end{array}$ & Cynodon nlemfuensis \\
\hline Racial group & Gyrolando & Lucerna & Hartón del Valle \\
\hline Average milk production (cow/day) & 14.09 & 14.12 & 5.36 \\
\hline Average range - $\mathrm{AT}\left({ }^{\circ} \mathrm{C}\right)$ & $21.6-28.3$ & $22-26.8$ & $19.5-26.8$ \\
\hline Average range - $\mathrm{RH}(\%)$ & $61.8-98.8$ & $69.6-88.9$ & $63.2-91.4$ \\
\hline Average range - SR (\%) & $8.9-34.8$ & $11.1-24.0$ & $7-25.9$ \\
\hline Average range - WS (m/s) & $0.94-2.35$ & $1.15-2.56$ & $0.8-1.7$ \\
\hline Average range - $\mathrm{PP}(\mathrm{mm})$ & $0-0.75$ & $0-1.05$ & $0-1.7$ \\
\hline Average range - $\mathrm{THI}$ & $88.4-105.7$ & $90.5-103.0$ & $85.9-102.0$ \\
\hline
\end{tabular}

AT: ambient temperature; RH: relative humidity; THI: temperature-humidity index; PP: precipitation; SR: solar radiation; WS: wind speed

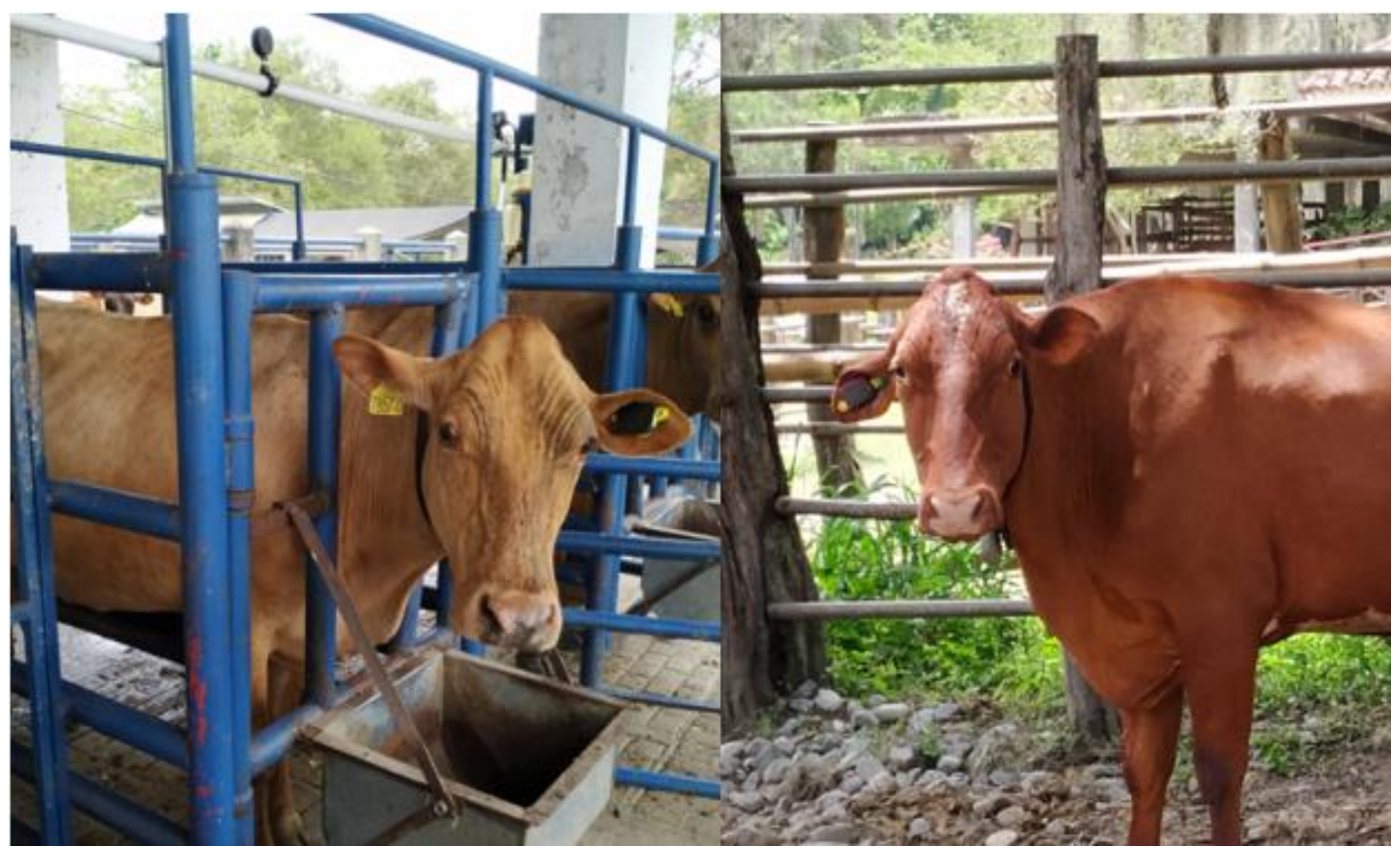

Figure 1 Wireless earmuff-type sensors to measure tympanic temperature.

\section{Results and Discussion}

Representative and significant correlations among climatic variables for each farm were identified. Among the main associations found, it was observed that AT was positively related with SR (0.67 to 0.78 ), WS (0.38 to 0.54 ), THI (0.99 in all farms), and negative associated with RH (-0.97 to -0.98$)$. Similarly, $\mathrm{RH}$ presented inverse relationships with
SR $(-0.62$ to -0.73$)$, WS $(-0.43$ to -0.55$)$, and THI $(-0.96$ to 0.97). Finally, THI showed a direct association with SR (0.68 to 0.78 ) and WS (0.37 to 0.53$)$. Similar direct associations between $A T, S R$, and $T H I$ and inverse relationship between maximum AT, Medium RH, and SR are reported in other studies (Jara et al 2016; Stürmer et al 2018). 
Correlations between climatic variables and animal tympanic temperature were moderate and positive for variables like AT (0.35 to 0.49$)$, SR ( 0.25 to 0.32$)$, THI (0.35 to $0.49)$, and negative for $\mathrm{RH}(-0.35$ to -0.49$)$. Low positive and negative associations were found with WS (0.05 to 0.23$)$ and PP $(-0.04$ to -0.21$)$, respectively. These results agree with the behaviors presented by Jara et al (2016), who found a direct relationship between tympanic temperature and $A T, S R, T H I$, and WS. The observed correlations confirm in a certain way the physiological relationship between tympanic temperature and its biometeorological adaptation (Da Silva and Campos Maia 2013), indicating that permanent tympanic temperatures recordings allow capturing a high volume of reliable data useful to identify physiological mechanisms of endogenous heat gain or loss at individual level (Collier and Gebremedhin 2015; Mayer et al 2016). These characteristics make tympanic temperature recording a more accurate alternative when evaluating the effect of caloric stress in dairy cows, compared to traditional indices such as ITH, which are indirect indicators that are not correlated with physiological responses in dairy cattle, especially in tropical conditions, and do not consider the individual animal effect (Da Silva et al 2007; Hoffmann et al 2020)
Adjusted tympanic temperature regression models for each farm are shown in Table 2. Only significant effects were considered in the final functions. Within each production system, the proposed models behaved similarly, indicating that $\mathrm{AT}, \mathrm{RH}$, and $\mathrm{THI}$ variables are all significant determinants of $\Pi$; however, models diagnostic coefficients indicated that regression equation constructed with AT variable presented the best adjustment in all cases (lowest AIC and BIC and highest $R^{2}$ ).

Comparing the significant effects between AT models, it can be observed that environmental influence on tympanic temperature varies across production systems. PP was a common effect in the estimated functions of farms 1 and 2, also SR was present in the functions of farms 2 and 3, meanwhile, WS was included in functions $1 \mathrm{y} 3$. The measurement day effect was significant in all cases. The influence of thermal comfort indices constructed with $A T, R H$, WS, SR and PP combine data on $\Pi$ have been previously reported in dairy cattle (Jara et al 2016; Arias et al 2018), confirming the influence of climatic variables (especially those associated with $\mathrm{AT}$ and $\mathrm{RH}$ ) on body temperature in grazing cows (Dikmen et al 2020).

Table 2 Estimated animal tympanic temperature regression models and their associated diagnostic coefficients found within each evaluated farm.

\begin{tabular}{|c|c|c|c|c|}
\hline Farm & Models* & AIC & $\mathrm{BIC}$ & $\mathrm{R}^{2}$ \\
\hline \multirow[t]{3}{*}{$1(n=2342)$} & $\mathrm{TT}=35.98+0.08 * \mathrm{AT}-0.08 * \mathrm{PP}-0.04 * \mathrm{WS}-0.0048 * \mathrm{D}$ & 2082.8 & 2123.1 & 0.86 \\
\hline & $\mathrm{TT}=39.46-0.02 * \mathrm{RH}-0.09 * \mathrm{PP}+0.00092 * \mathrm{SR}-0.05 * \mathrm{WS}-0.0048 * \mathrm{D}$ & 2139.8 & 2185.8 & 0.86 \\
\hline & $\mathrm{TT}=34.14+0.08 * \mathrm{THI}-0.08 * \mathrm{PP}-0.04 * \mathrm{WS}-0.0048 * \mathrm{D}$ & 2100.8 & 2141.1 & 0.86 \\
\hline \multirow[t]{3}{*}{$2(n=2693)$} & $\mathrm{TT}=36.16+0.07 * \mathrm{AT}-0.04 * \mathrm{PP}-0.0027 * \mathrm{SR}-0.0038^{*} \mathrm{D}$ & 1149.4 & 1190.6 & 0.42 \\
\hline & $\mathrm{TT}=39.10-0.01 * \mathrm{RH}-0.04 * \mathrm{PP}-0.0013 * \mathrm{SR}-0.01 * \mathrm{D}$ & 1205.1 & 1246.4 & 0.41 \\
\hline & $\mathrm{TT}=34.62+0.03 * \mathrm{THI}-0.04 * \mathrm{PP}-0.0027 * \mathrm{SR}-0.0031 * \mathrm{D}$ & 1154.1 & 1195.4 & 0.42 \\
\hline \multirow[t]{3}{*}{$3(n=3842)$} & $\mathrm{TT}=36.94+0.03 * A T-0.08 * \mathrm{WS}+0.0017 * \mathrm{SR}-0.0038 * \mathrm{D}$ & 844.5 & 888.2 & 0.63 \\
\hline & $\mathrm{TT}=38.17-0.01 * \mathrm{AT}-0.08 * \mathrm{WS}+0.0023 * \mathrm{SR}-0.0031 * \mathrm{D}$ & 902.5 & 946.3 & 0.62 \\
\hline & $\mathrm{TT}=36.29+0.01 * \mathrm{THI}-0.08 * \mathrm{WS}+0.0018 * \mathrm{SR}-0.004 * \mathrm{D}$ & 846.9 & 890.7 & 0.62 \\
\hline
\end{tabular}

TT: tympanic temperature; AT: ambient temperature; RH: relative humidity; THI: temperature-humidity index; PP: precipitation; SR: solar radiation; WS: wind speed; D: day; AIC: Akaike Information Criterion; BIC: Bayesian Information Criterion. $\mathrm{R}^{2}$ : Determination Coefficient.

*Only significant effects $(P<0.05)$ were included in the final model

Figure 2 present the estimated models performance against observed data in each farm. It can be seen that adjusted values follow a similar trend of the recorded tympanic temperature pattern. Measured data showed an average increase of $0.8^{\circ} \mathrm{C}\left(37.4\right.$ to $\left.38.2^{\circ} \mathrm{C}\right)$ from $6: 00-7: 00$ to 13:00 -16:00 h, meanwhile, with the adjusted information an average increase of $0,5{ }^{\circ} \mathrm{C}$ was calculated during the same period, where the maximum daylight and temperature are reached during the day. Once tympanic temperature reaches the maximum value, it begins to drop and stabilize close to 37.5 (estimated value) to $37.7{ }^{\circ} \mathrm{C}$ (observed value) on average. The thermoregulation process occurred at the end of the day and during the nighttime and lasted for 5 to 8 hours, being the most productive cows the ones that took the longest to stabilize (farm 1 and 2). In homeotherms, heat loss is an important transfer action through caloric regulation mechanisms to achieve homeostasis (Shu et al 2021), cows maintain an endogenous temperature balance by dissipating excess heat (at the point of maximum caloric load - midday and early afternoon-) or maintain homeothermy (during nighttime), as observed in each of the farms. If there is insufficient night cooling, the homeostasis mechanism is not regulated, and the cows enter the following day with an accumulated heat load (Gaughan et al 2008). In this way, the lower the possibility of thermal regulation at higher ambient temperatures, which affects the volume of milk produced (Becker et al 2020). The effect of dairy production on caloric metabolism is reviewed by Shu et al (2021). 

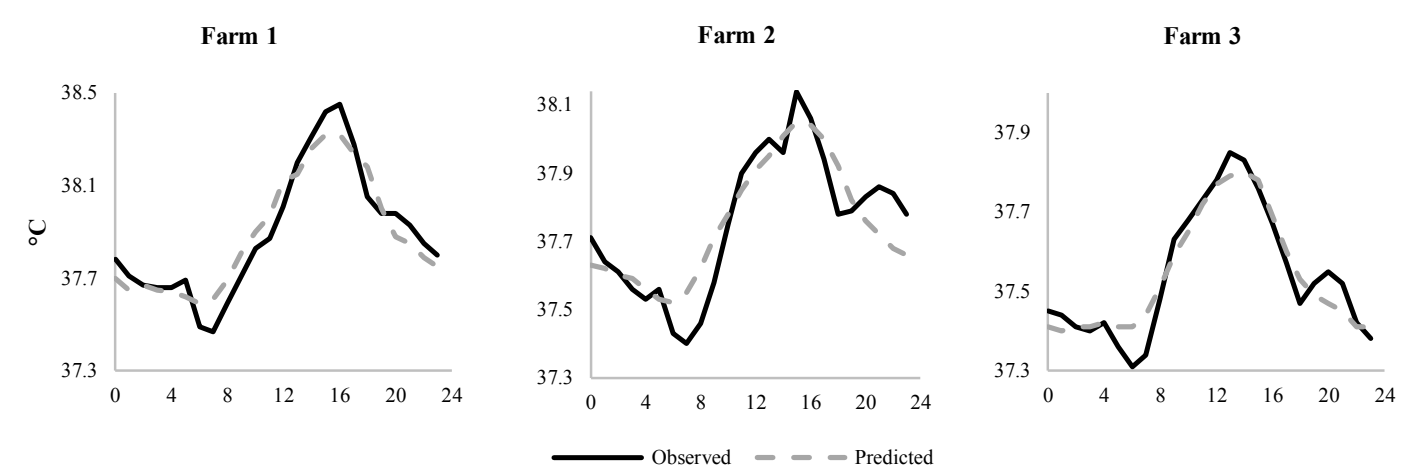

Figure $\mathbf{2}$ Average hourly observed and predicted animal tympanic temperature for each evaluated dairy system.

Correlations among environmental variables and tympanic temperatures obtained with the joint information of the three evaluated farms are shown in table 3. Magnitudes and signs of associations between climatic variables and tympanic temperatures are similar to that reported within each farm. Results showed that all studied climatic variables were significantly related to $\mathrm{TT}$; however, the highest associations were observed with $\mathrm{AT}, \mathrm{RH}, \mathrm{SR}$, and THI variables $(0.39,-0.36,0.29$, and 0.40 , respectively). These results reinforce the correlations found in individual farms. This could be attributed to similarities among climatic conditions within the study area (Molina et al 2016; Jara et al 2016)

Table 3 Spearman correlation between climatic variables and tympanic temperature found with the joint information of the production systems (estimated values and their significance are below and above the diagonal, respectively).

\begin{tabular}{lccccccc}
\hline Variable & AT & RH & PP & SR & WS & THI & TT \\
\hline AT & 1 & $<0.0001$ & $<0.0001$ & $<0.0001$ & $<0.0001$ & $<0.0001$ & $<0.0001$ \\
RH & -0.94 & 1 & $<0.0001$ & $<0.0001$ & $<0.0001$ & $<0.0001$ & $<0.0001$ \\
PP & -0.2 & 0.25 & 1 & $<0.0001$ & 0.2483 & $<0.0001$ & $<0.0001$ \\
SR & 0.73 & -0.67 & -0.09 & 1 & $<0.0001$ & $<0.0001$ & $<0.0001$ \\
WS & 0.43 & -0.42 & 0.01 & 0.12 & 1 & $<0.0001$ & $<0.0001$ \\
THI & 1 & -0.93 & -0.19 & 0.74 & 0.42 & 0.16 & 0.40 \\
TT & 0.39 & -0.36 & -0.08 & 0.29 & 0.0001 & 1
\end{tabular}

TT: tympanic temperature; AT: ambient temperature; RH: relative humidity; THI: temperatura -humidity index; PP: precipitation; SR: solar radiation; WS: wind speed.

General regression models estimated with the training data and evaluated with the validation set to predict tympanic temperature are presented in table 4 . Diagnostics coefficients also indicated that AT model presented the best fit to the data, being the AT, PP, SR, and measurement day the significant effects $(P<0.05)$. These results are similar to that found within farm 2 . The significant influence of climatic variables like ambient temperature and solar radiation on tympanic temperature was reported in multiparous Friesian $\times$ Holstein dairy cows (Jara et al 2016).

According to model 1 (table 4), without the influence of any climatic variable on dairy cows, their tympanic temperature is around $36.7{ }^{\circ} \mathrm{C}$ (intercept) which is close to the $37.5{ }^{\circ} \mathrm{C}$ value reported in Holstein and Holstein $x$ Montbeliarde cows managed under normal conditions and without environmental stressors (Arias et al 2018). However, the $0.8{ }^{\circ} \mathrm{C}$ bias suggests somehow that the model did not fit well at the origin. Partial regression coefficients of climatic variables indicated that for a one-unit increase in $\mathrm{AT}\left({ }^{\circ} \mathrm{C}\right)$ and keeping the other predictors constant, $\mathrm{TT}$ also increases 0.05 ${ }^{\circ} \mathrm{C}$; meanwhile, a unit increase in PP $(\mathrm{mm})$ and SR $\left(\mathrm{cal} / \mathrm{cm}^{2}\right)$ variables, reduce the $\mathrm{TT}$ in 0.01 and $0.0008{ }^{\circ} \mathrm{C}$, respectively. Direct association between ambient and tympanic temperature was also found in other studies (Jara et al 2016; Arias et al 2018); however, the influence of precipitation and solar radiation requires further research.

The mean square errors (MSE) attained when the validation data was evaluated in the general models are reported in table 4 . Model 1 presented the lowest value of 0.3044 , which is the average error made during tympanic temperature estimation with the validation data. This result is also evident in Figure 3, where an apparent linear relationship between predicted and observed tympanic temperatures suggests agreement between the related variables. 
Table 4 Tympanic regression models estimated with the training data from the unified information of the three evaluated systems

\begin{tabular}{|c|c|c|c|c|}
\hline No & General models & $\mathrm{AIC}$ & BIC & MSE validation set \\
\hline 1 & $\mathrm{TT}=36.69+0.05 * \mathrm{AT}-0.01 * \mathrm{PP}-0.0008 * \mathrm{SR}-0.0044 * \mathrm{D}$ & 2969.2 & 3016.3 & 0.3044 \\
\hline 2 & $\mathrm{TT}=38.62-0.01 * \mathrm{RH}+0.001 * \mathrm{SR}-0.013 * \mathrm{WS}-0.0045 * \mathrm{D}$ & 3028.7 & 3075.7 & 0.3055 \\
\hline 3 & $\mathrm{TT}=35.73+0.02 * \mathrm{THI}-0.01 * \mathrm{PP}-0.0009 * \mathrm{SR}-0.0045 * \mathrm{D}$ & 2980.1 & 3027.2 & 0.3050 \\
\hline
\end{tabular}

TT: tympanic temperature; AT: ambient temperature; RH: relative humidity; THI: temperature-humidity index; PP: precipitation; SR: solar radiation; WS: wind speed; D: day; AIC: Akaike Information Criterion; BIC: Bayesian Information Criterion. $\mathrm{R}^{2}$ : determination coefficient. MSE: mean square error obtained with validation set. Only significant effects were included in the final model $(P<0.05)$.

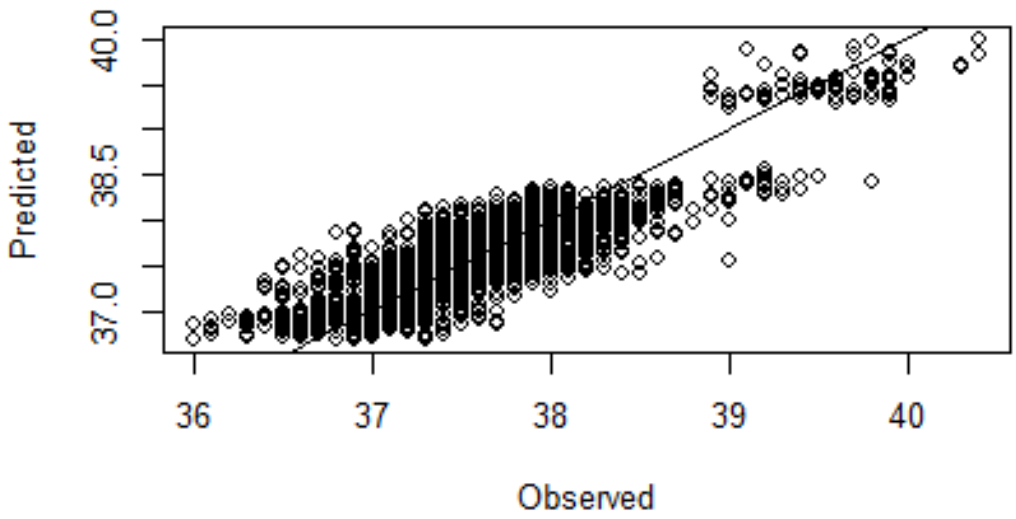

Figure 3 Predict Vs actual tympanic temperatures graph obtained with validation data and the general model 1.

Tympanic temperature influence on cow's milk production was also studied with Spearman correlations and linear and quadratic regressions for each dairy production system due to differences in average daily milk production per cow. Correlations between tympanic temperature and milk production were significant $(P<0.05)$ and variable in magnitudes among production systems, with positive values in farms where dairy cows averaged $14 \mathrm{Kg} /$ day $(r=0.46$ and 0.29 for farm 1 and 2, respectively) and negative values where the daily production averaged $5.4 \mathrm{Kg} /$ day $(r=-0.26$ for farm 3). These results suggest that cows with higher production levels presented higher tympanic temperatures, which is inverse with lower production animals. These findings are in line with the observation that increases in metabolic heat are associated with milk production synthesis, especially in high-producing dairy cows (Becker et al 2020), where different physiological mechanisms and temperature regulation events for dissipating heat during the day must occur (Jara et al 2016).

Table 5 shows the linear and quadratic models adjusted to predict individual milk production in each dairy farm. The predictors evaluated included the tympanic temperature, measurement day, and their quadratic terms. All the effects were significant in farm 1, while in farm 2, just the measurement day influenced individual milk production. No significant effects were found in farm 3, possibly for the minor milk production within this system (Gantner et al 2017).

Table 5 Regression equations to evaluate tympanic temperature influence on dairy cows productive performance

\begin{tabular}{|c|c|c|c|c|c|c|c|c|c|}
\hline \multirow[b]{2}{*}{ Farm } & \multirow{2}{*}{$\begin{array}{l}\text { Variable } \\
\text { predicted }\end{array}$} & \multirow[b]{2}{*}{ Intercept } & \multicolumn{4}{|c|}{ Predictors coefficients } & \multirow[b]{2}{*}{ AIC } & \multirow[b]{2}{*}{$\mathrm{BIC}$} & \multirow[b]{2}{*}{$R^{2}$} \\
\hline & & & TT & $\mathrm{D}$ & $\mathrm{TT}^{2}$ & $D^{2}$ & & & \\
\hline \multirow[t]{2}{*}{$1(n=67)$} & MP & -2229.6 & 115.2 & 1.35 & -1.48 & -0.10 & 267.9 & 282.8 & 0.70 \\
\hline & $P$-value & 0.0058 & 0.0062 & $<0.0001$ & 0.0071 & 0.0001 & & & \\
\hline \multirow[t]{2}{*}{$2(n=117)$} & MP & 14.71 & - & -0.07 & - & - & 361.8 & 372.8 & 0.68 \\
\hline & $P$-value & $<0.0001$ & NS & $<0.0001$ & NS & NS & & & \\
\hline \multirow[t]{2}{*}{$3(n=133)$} & MP & - & - & - & - & - & - & - & - \\
\hline & $P$-value & NS & NS & NS & NS & NS & & & \\
\hline
\end{tabular}

MP: milk production (L/day); TT: tympanic temperature; $\mathrm{D}$ : day; $\mathrm{TT}^{2}$ : quadratic tympanic temperature term; $\mathrm{D}^{2}$ : quadratic day term; AIC: Akaike Information Criterion; BIC: Bayesian Information Criterion. R²: Determination Coefficient. NS: Non-significant effect

The linear and quadratic statistical significance found in farm 1 suggests a tympanic temperature and day where the maximum milk production was reached during the experimental period, and then it began to fall. This is reinforced by the negative coefficients of quadratic terms (1.48 and -0.10 for tympanic temperature and measurement 
day, respectively). This relationship can be observed in Figure 4 , where the surface and contour plots obtained with the regression model of farm 1 are presented. Maximum milk production ranged between $17-18 \mathrm{Kg} /$ day attained with a tympanic temperature of 38.9 으 during the seventh day (values obtained solving for the unknown term in the first derivative set to zero). These results are also observed directly in both surface and contour graphs. The tympanic temperature is susceptible to minor variations in AT due to being close to the hypothalamus. Animals under farm 1 management, with $\mathrm{TT}$ close or higher than $38.9{ }^{\circ} \mathrm{C}$, could reduce their productivity, possibly by heat stress cases in its early stages (Baida et al 2021).

The measurement day was the only significant effect in farm 2, with a negative coefficient suggesting that individual milk production reduced $0.07 \mathrm{~L}$ during each experimental day. None effects influenced milk production in farm 3. The fact that tympanic temperature has not influenced the milk production of farms 2 and 3 can be attributed to several factors like animal management, agroecological localizations of the productive systems, breeds, and individual dairy production levels. Although farms 1 and 2 presented almost the same average individual production (14.09 and $14.12 \mathrm{~L}$ for farms 1 and 2 respectively), TT's effect on dairy performance was only reflected in the system with open grazing management. In contrast, no effect was observed in the silvopastoral system. Several studies report the benefits of the association of shrubs and trees on the grazing areas to provide shade and reduce the risk of caloric stress (Broom et al 2013; Bastos-Lopes et al 2016). In farm 3, the lack of tympanic temperature effect can be attributed to the low individual milk productions found within the system $(5.36 \mathrm{Kg} / \mathrm{day})$; according to Gantner et al (2017), low producing cows are less susceptible to heat stress. Finally, it is important to highlight that farms 2 and 3 (where no influence of tympanic temperature on milk production was observed) based their productivity with Colombian creole breeds (Lucerna and Harton del Valle), a genetic resource recognized for the presence of genes that provides them the ability to tolerate caloric stress and bear tropical conditions (De León et al 2019; Parra-Cortés and Magaña-Magaña, 2021).
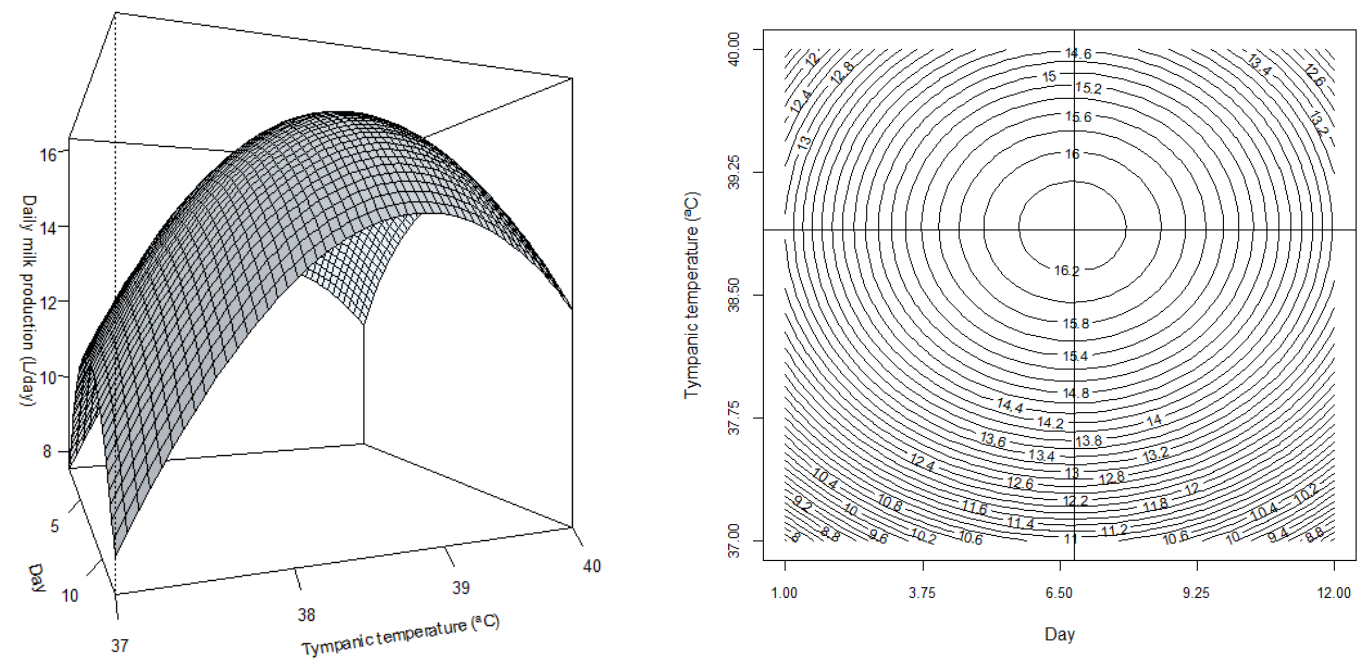

Figure 4 Surface and contour plots (left and right, respectively) of milk production effects in farm 1.

The variable association between tympanic temperature and milk production among farms reinforces the fact that heat stress impacts dairy cows differently, being the most productive animals the most affected. These results should motivate dairy farmers to evaluate the influence of weather conditions on their animals and establish particular heat stress mitigation mechanisms like the use of trees in grazing areas, implementation of cooling systems during milking, or improve diet and water quality and availability (Gantner et al 2017; Polsky and von Keyserlingk 2017), especially in high production dairy cows reared under tropical conditions.

The results of the present study showed that tympanic temperature determination through sensors allowed to capture of enough information to reliable assess the relationship between climatic conditions and the dynamic of heat gain and loss in dairy cattle, as suggested by Collier and Gebremedhin (2015) and Mayer et al (2016). Similar physiological logging tools to study animal response and behavior to environmental stressors are being used in animal science (Fahlman et al 2021).

\section{Conclusions}

In general, $\mathrm{TT}$ in grazing dairy cows was related to several climatic parameters; however, AT, PP, SR, and WS were the variables that most contributed to its determination among farms. It was found that cows accumulate heat during the day and dissipate it at nighttime, being the most productive cows the ones that took the longest to reach thermal homeostasis, making them the most susceptible animals to suffer caloric stress. The estimated animal tympanic temperature regression models presented an 
adequate adjustment among farms $\left(R^{2}=0.42\right.$ to 0.86$)$, which reliably infer the relationship between physiological and climatic variables.

The association analyses between $T T$ on daily milk production indicated that higher production dairy cows presented higher $T$ than lower production animals. The effect of TT on milk production estimation was not conclusive among farms, possibly due to factors like animal management, agroecological localizations of the productive systems, breeds, and individual dairy production levels.

The TT determination through sensors allows a better diagnosis of physiological temperature response in grazing dairy cows, contributing to the establishment of heat stress abatement practices and a more effective herd management.

\section{Conflict of Interest}

The authors declare that they have no conflict of interest.

\section{Funding}

This research was carried out as part of the project "Quantification of climate impacts on dairy cattle systems in the low tropic through data mining and modeling", Announcement 776-2017, MinCiencias.

\section{References}

Akbar MO, Ali MJ, Hussain A, Qaiser G, Pasha M, Pasha U, Akhtar N (2020) loT for Development of Smart Dairy Farming. Journal of Food Quality. doi.org/10.1155/2020/4242805

Arias RA, Herrera C, Larraín, R, González F, Mader TL, Velásquez (2018) Physiological and behavioural response of two dairy cows' genotypes during summertime in the central region of Chile. Austral Journal of Veterinary Sciences. doi.org/10.4067/S0719-81322018000100103

Baida BEL, Swinbourne AM, Barwick J, Leu ST, van Wettere WH (2021) Technologies for the automated collection of heat stress data in sheep. Animal Biotelemetry. doi.org/10.1186/s40317-020-00225-9

Barrera A, Angeli N, Machado L, Cardoso F, Gonzalez F (2015) Relationships between heat stress and metabolic and milk parameters in dairy cows in southern Brazil. Tropical Animal Health and Production. doi.org/10.1007/s11250-015-0804-9

Bastos - Lopes L, Eckstein C, Santos - Pina D (2016) The influence of trees on the thermal environment and behavior of grazing heifers in Brazilian Midwest. Tropical Animal Health and Production. doi.org/10.1007/s11250016-1021-x

Bergen RD, Kennedy AD (2000) Relationship between vaginal and tympanic membrane temperature in beef heifers. Canadian Journal of Animal Science. doi.org/10.4141/A00-033

Broom DM, Galindo FA, Murgueitio E (2013) Sustainable, efficient livestock production with high biodiversity and good welfare for animals. Proceedings of the Royal Society B. doi.org/10.1098/rspb.2013.2025

Becker CA, Collier RJ, Stone AE (2020) Invited review: Physiological and behavioral effects of heat stress in dairy cows. Journal of Dairy Science. doi.org/10.3168/jds.2019-17929

Collier R, Gebremedhin K (2015) Thermal biology of domestic animals. Annual Review of Animal Biosciences. doi.org/doi.org/10.1146/annurevanimal-022114-110659

Collier RJ, Baumgard LH, Zimbelman RB, Xiao Y (2019) Heat stress: physiology of acclimation and adaptation. Animal Frontiers. doi.org/10.1093/af/vfy031

Da silva RG, Campos Maia AS (2013) Principles of Animal Biometeorology. In: McGregor G (ed) Thermal Stress Indexes, vol 2 Springer, pp 207-227.

Da Silva RG, Morais DAEF, Guilhermino MM (2007) Evaluation of thermal stress indexes for dairy cows in tropical regions. Revista Brasileira de Zootecnia 36(4): 1192-1198.

Daltro AM, Bettencourt AF, Ximenes CAK, dos Santos Daltro D, \& dos Santos Pinho AP (2020) Efeito do estresse térmico por calor na produção de vacas leiteiras. Pesquisa Agropecuária Gaúcha. doi.org/10.36812/pag.2020261288-311

De León C, Manrique C, Martínez R, Rocha JF (2019) Genomic association study for adaptability traits in four Colombian cattle breeds. Genetics and Molecular Research. doi.org/10.4238/gmr18373

Dikmen S, Larson CC, De Vries A, Hansen PJ (2020) Effectiveness of tunnel ventilation as dairy cow housing in hot climates: rectal temperatures during heat stress and seasonal variation in milk yield. Tropical animal health and production. doi.org/10.1007/s11250-020-02309-3

Di Rienzo JA, Casanoves MG, Balzarini LA, Gonzalez EM. Tablada (2017) InfoStat versión 2017. Universidad Nacional de Córdoba-Argentina. http://www.infostat.com.ar/index.php?mod=page\&amp;id=34

Fahlman A, Aoki K, Bale G, Brijs J, Chon K, Drummond CK, Wisniewska DM (2021) The new era of physio-logging and their grand challenges. Frontiers in Physiology. doi: 10.3389/fphys.2021.669158

Gama LT, Martinez AM, Ginja C, Cañon J, Martin-Burriel I, Revidatti MA, Landi V (2020) Genetic Diversity and Structure of Iberoamerican Livestock Breeds. In Advances in Animal Health, Medicine and Production. doi.org/10.1007/978-3-030-61981-7_3

Gantner V, Bobic T, Gantner R, Gregic M, Kuterovac K, Novakovic J, Potocnik $K$ (2017) Differences in response to heat stress due to production level and breed of dairy cows. International Journal of Biometeorology 61: 1675-1685.

Gaughan JB, Mader TL, Holt SM, Lisle A (2008) A new heat load index for feedlot cattle. Journal of Animal Science. doi.org/10.2527/jas.2007-0305

Godyń D, Herbut P, Angrecka S (2019) Measurements of peripheral and deep body temperature in cattle-A review. Journal of thermal biology. doi.org/10.1016/j.jtherbio.2018.11.011

Hernández-Castellano LE, Nally JE, Lindahl J, Wanapat M, Alhidary IA, Fangueiro D, Almeida AM (2019) Dairy science and health in the tropics: challenges and opportunities for the next decades. Tropical Animal Health and Production. 10.1007/s11250-019-01866-6

Hoffmann G, Herbut P, Pinto S, Heinicke J, Kuhla B, Amon T (2020) Animalrelated, non-invasive indicators for determining heat stress in dairy cows. Biosystems Engineering. doi.org/10.1016/j.biosystemseng.2019.10.017

Jara IE, Keim JP, Arias RA (2016) Behaviour, tympanic temperature and performance of dairy cows during summer season in southern Chile. Archivos de Medicina Veterinaria. doi.org/10.4067/S0301732X2016000100014

Liu J, Li L, Chen X, Lu Y, Wang D (2019) Effects of heat stress on body temperature, milk production, and reproduction in dairy cows: a novel idea for monitoring and evaluation of heat stress - A review. Asian-Australasian Journal of Animal Sciences. https://doi.org/10.5713/ajas.18.0743

Mayer JJ, Davis JD, Purswell JL, Koury EJ, Younan NH, Larson JE, Brown-Brandl TM (2016) Development and characterization of a continuous tympanic temperature logging (CTTL) probe for bovine animals. Transactions of the ASABE. 59(2): 703-714.

Mylostyvyi R, Chernenko O (2019) Correlations between environmental factors and milk production of Holstein cows. Data. doi.org/10.3390/data4030103

Molina RA, Silva F, Perilla S, Sánchez H (2016) Caracterización del ambiente térmico para la actividad ganadera bovina en el Valle del Cauca, Colombia. Acta Agronómica. doi.org/10.15446/acag.v65n4.49018.

Morales-Vallecilla F, Ortiz-Grisales S (2018) Productividad y eficiencia de ganaderías lecheras especializadas en el Valle del Cauca (Colombia). Revista de la Facultad de Medicina Veterinaria y de Zootecnia. doi.org/10.15446/rfmvz.v65n3.76463

Parra-Cortés R, Magaña-Magaña M (2021) Technical-economic characteristics of bovine production systems of the Colombian creoles breeds Romosinuano and Hartón del Valle. Journal MVZ Cordoba. doi.org/10.21897/rmvz.2079 
Polsky L, von Keyserlingk AG (2017) Invited review: Effects of heat stress on dairy cattle welfare. International Journal of Dairy Science. doi.org/10.3168/jds.2017-12651

RStudio Team (2020) RStudio: Integrated development for R. RStudio, PBC, Boston, MA URL http://www.rstudio.com/.

Scharf B, Leonard MJ, Weaber RL, Mader TL, Hahn GL, Spiers DE (2011) Determinants of bovine thermal response to heat and solar radiation exposures in a field environment. International Journal of Biometeorology. doi.org/10.1007/s00484-010-0360-y

Sejian V, Bhatta R, Gaughan JB, Dunshea FR, Lacetera N (2018) Adaptation of animals to heat stress. Animal. doi:org/10.1017/S1751731118001945

Sellier N, Guettier E, Staub C (2014) A review of methods to measure animal body temperature in precision farming. American Journal of Agricultural Science and Technology. doi:10.7726/ajast.2014.1008
Shu H, Wang W, Guo L, Bindelle J (2021) Recent Advances on Early Detection of Heat Strain in Dairy Cows Using Animal-Based Indicators: A Review. Animals. doi.org/10.3390/ani11040980

Silva GM, Cangiano LR, Fabris TF, Merenda VR, Chebel RC, Dubeux JCB, DiLorenzo N, Laporta J (2021) Effects of providing artificial shade to pregnant grazing beef heifers on vaginal temperature, growth, activity, and behavior. Translational Animal Science. doi.org/10.1093/tas/txab053

Stürmer M, Busanello M, Velho JP, Heck VI, Haygert-Velho IM (2018) Relationship between climatic variables and the variation in bulk tank milk composition using canonical correlation analysis. International Journal of Biometeorology. doi.org/10.1007/s00484-018-1566-7

Vasconcelos de AM, de Albuquerque CC, de Carvalho JF, Façanha DAE, Lima FRG, Silveira RMF, \& Ferreira J 2020 Adaptive profile of dairy cows in a tropical region. International Journal of Biometeorology. doi.org/10.1007/s00484-019-01797-9 